\section{No, No, Nano}

Your siblings already know that you do stuff that they cannot, and probably don't even want to, understand. But their husbands and wives are more insistent. "What's all this nanotechnology stuff, anyway? Where can I buy some stock in it?" There are colleagues, too, who still ask after all this time, "Is this 'nano' thing real or just a bunch of hype? Isn't it just the same stuff we were already doing with a new label?"

Nanotechnology has passed a critical milestone in its path to universal acceptance, but let's put that in the context of an earlier wave of scientific evolution. Polymer science first emerged in the mid19th century, after Jons Jakob Berzelius's coining of the term "polymer." For nearly a century, however, commercial polymers still had prosaic names like vulcanized rubber, celluloid, rayon, nylon, or bakelite. During the Second World War, necessity gave birth to many inventions, including a material called polyethylene.

This stuff was in use for cheap consumer products very soon after the end of the war, and (at least in England) the name was shortened for commercial purposes to "polythene." Eventually, the largest tonnage application for the material, disposable shopping bags, became known to most of us simply as "poly bags."

Other polymers quickly followed. Polystyrene was used to make model airplanes, cars, and other objects that occupied the time of teenaged boys about as extensively in the 1960s as videogames do today. And the sixties would ne'er have made Carnaby Street's boutiques the very heart and soul of "swinging London" if not for the availability of poly vinyl chloride as a universal material for trendy clothing and fashion accessories. What had been a prefix in the technical vocabulary of organic chemistry entered the language as a word in its own right, after the public started to associate "poly" with modern, high-tech products-even though the phrase "hightech" was still a couple of decades in the future at the time.

It had taken a hundred years, but the marketing men had taken up the oncetechnical term and began using it for their own purposes. There was no longer any hope that its scientific meaning would ever restrain the commercial imagination, and products that contained no polymers at all were being registered with names that began with poly.

A construction filler-the stuff generically known as "spackle" in north America-was marketed to the emerging British DIY market (that was also busy producing the baby boom and needed to adapt its living quarters) under the brand name polyfilla ${ }^{\circledR}$. There was arguably a justification for that because this particular product contained natural polysaccharides, but the parent corporation followed up with dozens of other products, like polystrippa ${ }^{\circledR}$ to help remove old paint and polyclens ${ }^{\circledR}$ to clean the paintbrushes at the end of the job. These had no polymer content and were part of an extensive product family recognizable by the distinctively typefaced "Poly" at the beginning of each product's name.

$$
\begin{gathered}
\text { What's all this } \\
\text { nanotechnology stuff, } \\
\text { anyway? }
\end{gathered}
$$

Interestingly, today the company retains the name Polycell, but its products (many of which are now polymerladen) no longer deploy "poly" in their individual names. Many other companies trademarked names that included "poly" or "poli" during the 1950s and 1960s, and only a few of them still persist today. In one case, a product that has survived from this particular marketing era has its primary market niche among the nowaging baby-boomers: Super Poligrip ${ }^{\circledR}$. The marketer's first commandment, "Know thine audience," has clearly not been lost in the passing of time. Polymer science is still very much alive and well, but the days of poly-marketing have largely passed.

The term "nanotechnology" is not as precisely defined as "polymer," and some subjects that are definitely in the right length scale are not included in most people's usage. We were all studying atomic-scale defects for decades before the nano-age emerged, and for whatever reasons, subnanometer vacancies and dislocations are not usually included. There are also some things that have critical length scales over $100 \mathrm{~nm}$ that nevertheless still seem to be included within the definition, including many merely ultrafine-grained microstructures. Justice Potter Stewart of the U.S. Supreme Court summed up a similarly confusing situation in 1964: "I shall not today attempt further to define the kinds of material I understand to be embraced within that shorthand description; and perhaps I could never succeed in intelligibly doing so. But I know it when I see it." He didn't need an advanced microscope to see what he was talking about, though. He was discussing pornography.

A vague definition is just an invitation to a marketeer. The mega-marketing of nanoproducts has been with us for a few years now. We have been offered nanotechnological cosmetics, clothing, tennis rackets, and even hair-dryers. In most cases the justification, if any is offered, is that the products contain (gasp!) molecules. Apple's successful nano-branded iPod Nano ${ }^{\circledR}$ is one of a series of iPod products that embody giant-magnetoresistance-enabled memory devices with read-write heads that are truly nanoscale devices.

So how is it that only one member of the line bears the name Nano, and it is not even the smallest one? Whatever nanotechnology is, and whether or not it is real, it has certainly proven possible to sell it very effectively. The market has spoken.

But now, unheralded and unnoticed by most, a new development has occurred. In 2004, Dockers ${ }^{\circledR}$ brought us nanotechnological clothing - stain-resistant casual clothing that incorporated Teflon molecules (all of them actually a bit longer than the nanotechnology length-scale). Today, however, a search of the Dockers Web site reveals no mention at all of nanotechnology.

Have we entered the post-marketinghype era of nanotechnology? Has the public tired of it all, or are sales being impacted by health concerns now being associated with nanotechnology? In any event, polymer science has nicely survived the passing of market hype, and we can expect that nanotechnology will, too. "Poly" took a hundred years to reach the peak of its marketplace impact. "Nano" seems to have made it a couple of decades, but the pace of all technological development is accelerating.

Now, how do I explain all of that to my brother-in-law?

Alex KING 